\title{
PRESENÇA E PROPÓSITO DO CIRCO SOCIAL: UMA INICIATIVA POPULAR AUTÔNOMA
}

\author{
PRESENCIA Y PROPÓSITO DEL CIRCO SOCIAL: \\ UNA INICIATIVA POPULAR AUTÓNOMA \\ PRESENCE AND PURPOSE OF SOCIAL CIRCUS: \\ AN AUTONOMOUS POPULAR INITIATIVE
}

\author{
Giovana Tonini ${ }^{1}$ e José Francisco Miguel Henriques Bairrão ${ }^{1}$ \\ ${ }^{1}$ Universidade de São Paulo, Ribeirão Preto/SP, Brasil
}

\begin{abstract}
RESUMO: O circo, patrimônio artístico da humanidade, possui como modelo de transmissão tradicionalmente a família. Na contemporaneidade, a existência do circo se propaga também pelo circo social, que utiliza a arte circense como meio para o desenvolvimento integral de jovens marginalizados. Em Ribeirão Preto, há um caso (Sustentáculos) emergente na periferia, em que uma líder-circense-professora se apropria do circo para contribuir na formação psicossocial dos infanto-juvenis da sua comunidade. O objetivo do estudo foi investigar o arranjo do Sustentáculos tendo como esteio o circo social, a fim de comparar as propostas. A etnopsicanálise guiou o método através de observação e entrevistas; os colaboradores foram a líder e oito crianças; os encontros realizados semanalmente. Perceberam-se semelhanças fundamentais, porém um caráter mais pedagógico e estruturado no circo social, por trabalharem em rede e com apoio financeiro. No Sustentáculos, há uma marca clara do artístico propriamente dito, um viés políticocontestador e autonomia do projeto.
\end{abstract}

PALAVRAS-CHAVE: Circo; Circo social; Projeto social; Arte; Etnopsicanálise.

RESUMEN: El circo, patrimonio artístico de la humanidad, es tradicionalmente transmitido entre familias. Actualmente, su existencia también se propaga a través del circo social, que utiliza el circo como un medio para el desarrollo integral de jóvenes marginados. En Ribeirão Preto, hay un caso emergente (Sustentáculos) en la periferia, dónde una artista y maestra se apropia del circo para contribuir a la formación psicosocial de jóvenes en su comunidad. El objetivo del estudio fue investigar el Sustentáculos teniendo como pilar principal el circo social, para comparar las propuestas. Etnopsicoanálisis guió el método a través de la observación y las entrevistas; los colaboradores fueron el líder y 8 niños; las reuniones se realizaron semanalmente. Se observaron similitudes, pero un carácter más pedagógico y estructurado en el circo social, porque hay una rede y apoyo financiero. En Sustentáculos, hay una clara marca de lo artístico en sí, un sesgo político-concursante y autonomía total.

PALABRAS-CLAVE: Circo; Circo social; Proyecto social; Arte; Etnopsicoanálisis.

ABSTRACT: The circus, artistic patrimony of humanity, traditionally has the family as transmission model. Currently, the circus' existence also spreads through the social circus, which uses circus art as a means for the integral development of marginalized young people. In Ribeirão Preto, there is a case of this (Sustentáculos) in the periphery, in which a circus artist-teacher-leader appropriates the circus to contribute to the psychosocial education of the youth from her community. The aim of the study was to investigate Sustentáculos, having as mainstay the social circus in order to compare the proposals. Ethnopsychoanalysis guided the method through observation and interviews; the collaborators were the leader and eight children; the meetings were held weekly. Important similarities were noted, but a more pedagogical and structured character was noted in the social circus, for working in a network and with financial support. As for Sustentáculos, there is a clear mark of the artistic itself, a politicalcontestant bias and autonomy.

KEYWORDS: Circus; Social circus; Social project; Art; Ethnopsychoanalysis. 


\section{Introdução}

O circo, arte milenar da existência humana, é caracterizado sobretudo pela sua relação com o fantástico e por propiciar o sonhar e maravilhar-se da plateia (Souza, 2013) a partir de um espetáculo cujos artistas desafiam a gravidade, possuem habilidades superdotadas de equilíbrio ou força, distorcem a realidade através da mágica e ilusionismo, arrancam risadas por atuações cômicas ou grotescas. Para Silva (1996), a arte circense pode ser considerada o espetáculo mais antigo do mundo, de tal modo que Ziegler (1980) destaca o papel matricial da família na manutenção e continuidade do circo:

O circo é o último vestígio de um saber antigo, existencial e iniciático. Esse saber, essa arte ancestral e única que é o circo, só se perpetua graças a dois mecanismos: a transmissão do saber de pai para filho, e o ensino proporcionado por uma escola. (1980, citado por Silva, 1996, p. 1)

Em termos de fortalecimento e propagação, o circo ganha destaque a partir do último quarto do século XVIII, quando se constituíram as dinastias circenses na Europa Ocidental, oriundas dos artistas ambulantes e saltimbancos (Silva, 1996). A partir disso, ao longo do XIX, passam a espalhar-se ao redor do mundo reproduzindo aquilo que dominavam: e desbravando os Novos Mundos através do circo. No Brasil, famílias europeias construíram impérios que até hoje vigoram e marcam o Circo Brasileiro; inicialmente, apresentavam-se em praças e teatros, depois passaram a juntar os equipamentos no lombo de burros, trens e caravanas, a fim de levar os espetáculos teatrais, ilusionistas e comediantes para todo o país (Castro, 2003).

Dessa forma, o circo clássico possui uma estrutura familiar - transmitida de geração em geração entre os artistas - e nômade - por estarem continuamente em trânsito e apresentando-se em diferentes locais. As técnicas e práticas, tal como os valores, conhecimentos e história do circo são difundidos e aprendidos oralmente: a fim de que internalizem o saber circense em sua totalidade - para além dos exercícios e atuações, mas principalmente no que tange à sabedoria própria que essa arte carrega (Oliveira \& Cavedon, 2013). Nesse modelo tradicional, cujo expoente foi o século XX, não apenas a família civil tinha de cumprir a função social de ensinar circo aos seus filhos, uma vez que a criança circense, no chamado "circo-família", era vista como responsabilidade de todos. Desse modo, era comum na época os pequenos referirem-se aos membros da trupe como "tio" e "tia”, da mesma maneira que, se ficassem órfãos(as) ou fossem abandonados pelos pais, seriam certamente amparados pela família circense (Silva, 1996).

Considerando a atividade circense, em si, é válido destacar que a sua matriz é o corpoo corpo como um organismo vivo que vive, experimenta e desafia seus limites. O circo traz às artes o corpo como fator espetacular: $\mathrm{e}$, assim, $\mathrm{o} / \mathrm{a}$ artista não apenas representa um papel através do seu físico, mas depara-se constantemente com práticas que visam a fortalecer suas habilidades - e dificuldades - em seu ritmo e pulsação próprios, para então no espetáculo vivenciá-las e exibi-las para o público (Bolognesi, 2001). Assim, antes de ser compreendido e racionalizado intelectualmente pelos artistas, o circo adentra-os via experiência, através do sentir e viver na pele, por meio do modo mais primitivo possível - o corpóreo - de tal maneira que marca e transforma os artistas como sujeitos - modificando a maneira com que se percebem e percebem o mundo. Portanto, em síntese, há um entrelaçamento entre artista e sujeito, entre circense e pessoa, visto que o circo transcende os limites das lonas e habita intrinsecamente os seus aprendizes (Pereira \& Maheirie, 2016). 
Tendo em conta tamanhas potencialidades, no início dos anos noventa foi criado um modelo de intervenção e ação social que utiliza as artes circenses como meio para trabalhar, principalmente, com crianças e jovens de classes populares. O chamado circo social nasceu na província do Quebec através de uma parceria do renomado Cirque du Soleil com o organismo de cooperação internacional Jeunesse du Monde, que juntos constituíram o programa de alcance mundial Cirque du Monde (Lafortune \& Bouchard, 2011). Embora tenha sido idealizado originariamente para intervir com infanto-juvenis da periferia, há diversos públicos atendidos ao redor do mundo pelo circo social: mulheres vítimas de violência, adultos(as) com dificuldades de aprendizagem, refugiados(as), detidos(as) etc. Afinal, o circo é aquele que fala com todos - homens e mulheres, com prestígio social ou não, novos e velhos, com potencial atlético ou não - basta a vontade de se mover e a capacidade de fazer com que seus parceiros também se movam, visto que são um coletivo (Rivard, Bourgeault, \& Mercier, 2010).

O circo social é definido como uma "metodologia pedagógica de ação social” (Lafortune \& Bouchard, 2011, p. 13) que objetiva, através do circo e de uma equipe profissional treinada e comprometida, prover o desenvolvimento integral - em termos de crescimento pessoal e social - e a maior inclusão dos participantes (jovens de periferia) na sociedade (Lafortune \& Bouchard, 2011). Ao contrário do circo tradicional, não visa à obtenção de resultados impecáveis e a um espetáculo magnífico, mas sim a busca pela cidadania (Lobo \& Cassoli, 2006). Assim, não se trata de uma lógica produtivista atida aos resultados, mas sim uma processual, uma vez que a potência do circo social reside na experiência vivenciada ao longo do caminho e decurso das atividades (Rivard et al., 2010).

Acerca das contribuições, o circo social favorece sobretudo o desenvolvimento da autoestima pois a essência do circo é encarar situações que parecem impossíveis ou difíceis e, com a prática e engajamento, torná-las possíveis; dessa forma, cada vitória aumenta gradativamente a autoconfiança do/da jovem e o/a possibilita conhecer suas fortalezas - especialmente a de que ele é capaz de superar e progredir. Outro ganho notável é o desenvolvimento de habilidades sociais, tal qual a comunicação e empatia, uma vez que o/a circense se constrói a partir da ajuda mútua e, portanto, no coletivo - o que implica circunstâncias que suscitam posturas e funcionamentos básicos a nível de uma organização social: como respeito ao jeito e tempo do próximo; colaboração e confiança entre o grupo; resolução conjunta de problemas (Lafortune \& Bouchard, 2011). Assim, unindo a expressão artística e trabalho em equipe que marcam o circo, há efeitos significativos na saúde física e mental dos indivíduos e comunidades que estão inseridos, na medida em que se tornam mais empoderados de suas próprias vidas - pela disciplina, perseverança e criatividade trabalhadas no circo (Spiegel, Breilh, Campaña, Marcuse, \& Yassi, 2015). Empoderar-se na periferia, realidade dura em termos de condições político-sociais, significa criar e ampliar recursos para lidar com cargas de deslocamento e perda; em um estudo que analisou quatro programas de circo social no Canadá, com crianças e adolescentes em vulnerabilidade social, o principal ganho destacado pelos participantes foi uma maior possibilidade de superar traumas envolvendo experiências pessoais ou familiares na marginalização (Spiegel \& Parent, 2018).

No entanto, para que os frutos do circo social tenham chances significativas de concretizarem-se na vida de crianças e jovens de periferia, o documento produzido pelo Cirque du Soleil (2011) nomeado "Guia do Educador de Circo Social" postula algumas diretrizes que, em tese, aumentam a eficácia da intervenção. Idealmente, as ações de circo social devem ocorrer numa instituição que esteja de acordo com as leis do país, que se responsabiliza 
por obter apoio financeiro governamental ou privado para a intervenção e que oferece um local seguro para os treinos e reuniões, além de materiais de circo e de gestão. A partir dela ocorrem as aulas regulares, realizadas por uma equipe de instrutores de circo artistas circenses dispostos a ensinar um determinado público - e educadores de circo social - personagens locais da comunidade, contratados pela instituição local, que atuam como ponte entre o projeto de circo e os participantes (Lafortune \& Bouchard, 2011).

Tendo o esboço geral da dinâmica do Cirque du Monde, há ainda considerações específicas para cada um desses nichos - instituição, instrutores e educadores de circo social - que preconizam seus deveres e competências. Por exemplo, é responsabilidade da instituição local conduzir a seleção dos educadores de circo social e garantir a segurança de todos os envolvidos, a partir de planos de urgência e emergência; quanto ao instrutor, é indispensável paixão e talento, assim como a consciência de que será um modelo para os participantes; no que tange ao educador de circo social, deve causar entusiasmo nos jovens para que superem suas barreiras, igualmente convidá-los a se envolverem no coletivo de forma horizontal e, principalmente, sinalizar as semelhanças entre as lições aprendidas no circo e a realidade da sociedade - ou seja, elas podem ser aplicadas à vida, como argumentam os autores Lafortune e Bouchard (2011):

A ideia geral a ser transmitida é que as aprendizagens adquiridas durante as aulas podem ser aplicadas na vida do dia a dia, que elas podem servir para desenvolver habilidades sociais, definir objetivos de vida, cuidar de si e dos outros, adotar atitudes positivas face às vitórias e derrotas da vida, pois estas se sucedem de modo imprevisível. (p. 36)

Estes norteadores do circo social são de extrema importância por procurarem assegurar uma relativa uniformidade da marca da intervenção, independentemente do local do mundo. Porém, a intenção do circo social não é ditar o que é problemático e que deve ser transformado em determinado grupo de indivíduos de uma comunidade, mas sim ouvir as necessidades e potencialidades de cada um deles para, então, estimular o envolvimento no projeto em questão (Hannes \& Uten, 2018). A partir deste viés é que cada projeto adquire sua especificidade. No Brasil, a Rede Circo do Mundo do Brasil, criada em 1998, reúne 22 instituições de quatro regiões brasileiras que recebem crianças e adolescentes em situação de risco e vulnerabilidade social. Trabalham a cidadania, a integração dos excluídos e o resgate das raízes culturais, visando sobretudo a fortalecer os jovens para que transcendam as generalizações preconceituosas que perpassam suas identidades - como "pobre e favelado" como sinônimo de bandido, drogado, preguiçoso ou incapaz - e descobrirem por eles próprios quem são, tal como as oportunidades que possuem. A Rede espera que os/as participantes empoderem-se de suas vidas, ampliem seus horizontes e construam, assim, uma sociedade firmada na equidade e justiça (Revista Circo do Mundo Brasil, 2003).

Distante da organização formal e categórica do circo social e, também, desprovido do amparo nacional da Rede Circo do Mundo do Brasil, está o projeto de circo Sustentáculos: vigorante há 25 anos na periferia de Ribeirão Preto, encabeçado e dirigido por uma única mulher circense que é moradora do bairro e oferece três aulas de circo semanalmente às crianças e jovens da comunidade, no quintal de sua própria casa. A promotora da iniciativa nunca conseguiu uma parceria pública ou privada para financiar o projeto - em termos de materiais e estrutura do local -, mas nem por isso desistiu, uma vez que encontrou maneiras alternativas e colaborativas com os pequenos para a sobrevivência do circo. 
Levando em conta a originalidade da iniciativa que, em parte, se contrapõe aos pilares estruturais do circo social por ser um serviço que atua isoladamente - desamparado de uma Rede - nos moldes que a moradora da comunidade possui condição de ofertar, é válido investigar o que faz deste circo um circo social. Ou seja, um circo social que vive independente da existência da estrutura ideal para as aulas devido ao local improvisado e materiais limitados; da presença de uma equipe profissional, visto que há uma única figura que é a circense, a professora, a idealizadora e mantenedora do projeto; da assistência de parcerias financeiras. Ademais, embora a aparente simplicidade do projeto, ele atua como uma entidade viva, cuja força advém de uma líder que possui o circo entrelaçado em sua existência e em seus modos de atuação no mundo, a tal ponto que o devolve para sua comunidade em forma de espetáculo e inclusão circense. Constitui-se, assim, uma agregação coletiva, uma família circense da comunidade que recebe crianças e adolescentes de distintas gerações: provando-se como um meio para o desenvolvimento psicossocial dos infanto-juvenis.

Sendo assim, o projeto atua como uma instrumentalização dos jovens em direção ao rompimento da marginalização social. E seu brilhantismo reside na organicidade com que nasceu e cresceu, autoalimentando-se, autossustentando-se, autoafirmando-se. Em busca de uma sociedade cujas estrelas sejam a equidade e justiça, movidas por um público crítico que as exija e que se empenhe cotidianamente para que as oportunidades, de fato, sejam possíveis e acessíveis aos que estruturalmente são deixados às margens. É de fundamental importância, para a psicologia social, a compreensão desta iniciativa popular, autônoma, artística e política, assim como das relações interacionais - entre os sujeitos e entre os conteúdos que habitam eles próprios - que a configuram. Afinal, o circo é uma arte e cultura popular, historicamente não identificado às elites, mas ao povo. E a esse povo promove não apenas um lazer, mas um sonhar propiciado pela autonomia e capacidade de realização vivenciadas na constante prática circense, de erros e superações. Portanto, o circo da periferia para a periferia não atua unicamente como uma forma de resistência dessa prática cultural, oriunda de famílias pobres e nômades, mas como uma forma de empoderamento, de fato. Um meio de tomar para si um fazer, perceber-se como dono de sua própria história, o que politicamente traz a nota do protagonismo e do devir.

O objetivo deste estudo foi investigar o arranjo do projeto de circo Sustentáculos considerando a história da líder e os efeitos psicossociais do circo sob esse grupo, tendo como esteio a literatura de circo social, a fim de compreender as semelhanças e convergências entre as propostas e suas possíveis raízes.

\section{Metodologia}

\section{Delineamento}

A etnopsicanálise, abordagem teórica utilizada no estudo, conjuga a antropologia e a psicanálise em um encontro pluridisciplinar - ou seja, considerando as contribuições de cada área em sua totalidade e integralidade, e não apenas em suas intersecções. Os teóricos que inicialmente notaram a potencialidade desta confluência foram Róheim e Devereux, sendo o primeiro considerado o fundador da abordagem - por ter estreado a análise de 
dados etnológicos à luz da psicanálise - e o segundo o que a batizou de "etnopsicanálise”. Em síntese, eles esforçavam-se para contemplar as duas correntes conjuntamente: vigiando-se quanto ao olhar "universalizante" da psicanálise, julgado assim por alguns antropólogos, e desfrutando de uma investigação cultural, o que costuma ser ignorado pelos psicanalistas (Leal de Barros \& Bairrão, 2010).

As possibilidades etnopsicanalíticas são promissoras na medida em que a psicanálise convida o pesquisador a desenvolver "um olhar profundo e complexo sobre o outro (e outro em nós)" (p. 51) ao mesmo tempo em que a antropologia o ampara para compreender esse outro em sua alteridade, na configuração cultural em que está inserido - que não necessariamente é comum entre pesquisador e pesquisado (Leal de Barros \& Bairrão, 2010). Portanto, sugere que as pessoas sejam entendidas fundamentalmente como partes da cultura, que dessa forma não é algo externo e existente em si mesmo, e o mesmo equivale para o psiquismo humano, que deve ser percebido como constituído (também) por elementos culturais (Pagliuso \& Bairrão, 2015).

Para uma aplicabilidade legítima da etnopsicanálise, que aborda os universos pessoal e social do indivíduo, o/a pesquisador(a) deve atentar-se às distintas formas de escuta, uma vez que as formas de expressão do sujeito não se restringem às objetivas, observáveis e verbalizáveis. Para Lacan, é impossível o sujeito contar-se apenas verbalmente, pois o discurso inconsciente transcende o dito, emergindo por outras formas de enunciação que não a linguagem - as quais são passíveis de serem percebidas e escutadas (Pagliuso \& Bairrão, 2015). Nesse sentido, a escuta participante é um artifício potente para guiar a interação em campo e buscar o resgate de partes do discurso não ditas, a fim de ouvir também as dimensões inconscientes carregadas de significação - afinal, nas palavras de Bairrão (2005): "Muitas vezes é inútil encontrar um significado verbal por trás de um gesto ou procedimento, significantes" (p. 446). Tal instrumento tem raízes na observação participante de Malinowski e, como herança dessa prática, destaca a relevância da imersão do/da pesquisador(a) no campo e a descrição detalhada sobre suas impressões (Bairrão, 2005).

\section{Participantes e contexto}

Participaram do estudo a promotora da iniciativa do circo social Sustentáculos e oito infanto-juvenis que frequentam assiduamente as aulas, sendo a maioria deles do gênero feminino ( 7 meninas e 1 menino), a faixa etária dominante de 10 a 12 anos e as crianças mais nova e mais velha com 5 e 13 anos, respectivamente. Os encontros ocorreram na residência da idealizadora, localizada num bairro periférico de Ribeirão Preto, ao longo das aulas de circo e igualmente em momentos particulares com a líder.

\section{Procedimento}

A coleta dos dados ocorreu semanalmente por 2 anos. Para a apreensão do fenômeno e obtenção dos dados, foram realizadas observação somada à escuta do campo e entrevistas semiestruturadas, sendo compreendidos assim os princípios etnográficos e a escuta participante, respectivamente. Embora a riqueza das entrevistas seja indiscutível, sem a observação do campo não haveria etnopsicanálise - que é concebida pelo casamento entre a Antropologia e Psicanálise, que unem suas principais heranças: o etnografar e o ouvir. Tal casamento foi fundamental para a percepção deste circo, que está imerso numa 
dinâmica relacional e comunidade cultural específica. Nesse sentido, para Laplantine (2004), etnografar é, basicamente, uma atividade visual cujo desafio para o pesquisador é romper com as convenções e valores sociais pertinentes à sua época, cultura e meio social: e que o atravessam e influenciam, inconscientemente, acerca do que olhar e como olhar. Como coloca o autor: "Ver é, na maioria das vezes, por memorização e antecipação, desejar encontrar o que esperamos e não o que ignoramos ou tememos" (p. 14). Assim, a etnografia não é da ordem desse imediatamente visto, mas da visão mediada, distanciada, reavaliada e potencializada pela escrita. Não se trata de ver, mas de olhar: de demorar no que se vê, de distinguir e discriminar o que se vê, de manifestar interesse e atenção ao que se vê, de intensificar aquele primeiro ver. E, a partir disso, a descrição etnográfica consiste no "fazer ver" através da escrita, ou seja, compartilhar a cultura e lógica de determinado grupo com um leitor(a) que obviamente não vivenciou o campo com o/a pesquisador(a) (Laplantine, 2004). Sendo assim, baseando-se no movimento do olhar, as impressões, percepções e descrições de episódios marcantes foram dispostas em um caderno de campo, considerando sua importância para a etnografia (Fonseca, 1999).

A respeito das entrevistas semiestruturadas, essa configuração prova-se rica uma vez que as perguntas, dispostas em tópicos prévios que possuem a finalidade de orientar a condução da entrevista, atuam como disparadores para discursos dos colaboradores (Manzini, 2004). Tais discursos, por sua vez, são ouvidos para além do seu conteúdo verbalmente dado, mas pelo viés da escuta participante: que se atém principalmente aos significantes que residem no não dito, no inconsciente (Bairrão, 2005). Assim, atos falhos, surpresas, zonas de silêncio, estranhamentos, nervosismos e a própria linguagem corporal são ouvidos e tomados como relevantes pelo pesquisador a fim de tentar preencher as lacunas da história ou de uma demanda do indivíduo - considerando como ele a internalizou, a representou, a significou - e assim, tentar aproximar-se do seu mundo interno.

A efeito de temáticas abordadas, as entrevistas realizadas com os alunos seguiram tópicos-guia que tangenciassem o circo, como por exemplo: o que aprendem, porque gostam de frequentar o projeto, o que sentem por fazerem parte daquele grupo, o que levam do circo para o espetáculo da vida e como a experiência do projeto influencia as percepções de mundo e deles próprios. No que se trata da fundadora do projeto, as questões foram em torno de compreender a sua biografia e como essa se cruzou com o circo - como por exemplo, por que circo? E não qualquer outra intervenção artística? O que a encantou no circo e o que mais fez sentido nesse encontro? Qual o espaço que o circo possui em sua vida? Por que ela usa o circo para tentar mudar a vida de crianças e jovens do bairro? Por que acredita que o circo é relevante para as demandas do seu recorte social?

As informações da observação e escuta do campo foram devidamente organizadas semanalmente e, juntamente com os conteúdos e reverberações subjetivas das entrevistas audiogravadas, foram tomados como dados do campo.

\section{Análise de dados}

A análise dos dados baseou-se essencialmente nas entrevistas - vivências e percepções durante as entrevistas e igualmente as gravações obtidas - e observação do campo - organizada no diário de campo, por meio da descrição etnográfica. Através da escuta repetidas vezes das entrevistas, da leitura sistemática das descrições etnográficas e da própria vivência do campo concomitantemente a esse processo, as considerações e demandas 
dos colaboradores foram gradativamente emergindo e tomando forma. Esse conteúdo foi trabalhado e refletido pela via da etnopsicanálise, tendo sido suporte novamente a escuta participante, que complementou a leitura dos temas emergidos uma vez que foi considerado não apenas o que foi dado verbalmente ou visualmente, mas também as associações livres, os implícitos, as fantasias, as projeções e, em suma, o não dito (inconsciente).

Para além desses conteúdos e demandas mais relevantes para e sobre os colaboradores, outro grande motor de impressões numa pesquisa que possui como uma de suas âncoras a psicanálise é a transferência. Nas palavras de Freud (1912/1996): “a psicanálise faz em seu favor a reivindicação de que, em sua execução, tratamento e investigação coincidem” (p. 152) e, se a transferência é condição de um tratamento, igualmente se faz presente na investigação - já que tratamento e investigação coincidem (Elia, 1999). A pesquisa psicanalítica está imbricada na prática da psicanálise desde as primeiras experiências e postulados freudianos, uma vez que a metodologia desse tipo de pesquisa é oriunda da experiência, de um mistério que é sondado e investigado a partir de um corpo teórico - a psicanálise - mas principalmente, a partir de alguém que o experiencia, que o sonda e que o investiga. Nessa perspectiva, o pesquisador é o primeiro sujeito da pesquisa e seu campo de trabalho é escutado a partir da transferência (Ravasio, 2014). Por isso, num estudo etnográfico instruído psicanaliticamente, não há espaço para o ego do pesquisador sentir-se superior, de certa forma, ao sujeito ou à comunidade pesquisada, de modo que o fenômeno - as cargas de emoção e tensão emergidas a partir das demandas apresentadas - não se mostra apenas para quem se pesquisa, mas também intrinsecamente para aquele que a conduz. Daí a relevância da relação transferencial em campo, que é inevitável e, por tal razão, deve ser acolhida positivamente, como mais uma forma de enunciação e comunicação entre sujeitos empíricos (Bairrão, 2015).

\section{Resultados}

\section{O nascimento}

O circo Sustentáculos é fruto da iniciativa própria e singular de uma mulher de origem circense; sendo assim, refletir sobre o início desta causa está automaticamente relacionado à história dela: o projeto começa nela, mais precisamente, no encontro dela com o circo que a habita. Ela é a primeira e grande estrela desse espetáculo.

A líder é filha de um casal de circenses que, além dela, conceberam mais três filhos. O pai era o esteio do circo, enquanto a mãe conheceu e engajou-se nesse universo e prática através do marido. No entanto, quando ela tinha dois anos, os pais separaram-se bruscamente e os filhos foram viver com o pai, de tal modo que não tinham contato algum com a mãe. Junto com este rompimento entre o casal, houve também uma ruptura com o circo: ambos deixaram de exercê-lo. Dessa forma, a arte circense pode ser entendida como um símbolo de amor fértil entre os pais da artista, uma vez que pertenceu à realidade da dinâmica familiar enquanto estavam todos unidos. Assim, a estrela do Sustentáculos não recebeu ativamente a carga iniciática do circo através de seus familiares - em termos de aprendizado concreto das atividades - mas, de certa forma, é algo que a imprimiu significativamente e teve presença em suas relações matriciais, infância e meio social, o que 
foi suficiente para que o circo se inscrevesse em sua alma e destino. Então, embora não praticasse enquanto criança, ela conta que cresceu rodeada de materiais circenses em casa e da "gente do circo", colegas de seu pai, o que fermentou uma curiosidade de sua parte em conhecer e experimentar, de fato, aquilo. Assim, na adolescência, matou seu desejo quando iniciou os primeiros cursos teóricos e práticos de arte circense.

A partir dessa formação, que lhe possibilitou assumir e empoderar-se da sua identidade como sujeito circense, a líder iniciou suas atividades profissionais envolvendo o circo. Dentre algumas ocupações que exerceu, é válido pontuar uma delas, visto que possui relação direta com o Sustentáculos. A artista atuou num projeto social oferecido e bancado financeiramente pela prefeitura, chamado Ribeirão Criança, que existiu por um período na comunidade: o empreendimento era destinado aos moradores da região - crianças, jovens e adultos - e disponibilizava aulas de circo, teatro, dança, capoeira, música etc. Ela narra que naquela época o bairro tinha "mais vida" e que a longo prazo o projeto deixou ganhos observáveis na própria comunidade, como a diminuição da criminalização e tráfico de drogas. No entanto, o Ribeirão Criança teve um corte brusco com a mudança da gestão municipal e isso gerou "um buraco na rotina" dos envolvidos, de tal modo que, nas palavras dela, "alguns alunos começaram a mexer com coisa errada". As consequências disso vieram com uma chacina no bairro, em que dois de seus ex-alunos de circo morreram por comprometerem-se com instâncias maiores.

O ocorrido a mobilizou imensamente e a fez sentir-se culpada - "será que com o circo, isso ainda assim teria acontecido?" ela se questionou, durante a conversa - de maneira que, frente a isso, sentiu que simplesmente não podia permanecer inerte. Então, decidiu trazer as crianças para sua casa e restabelecer as aulas de circo - o que marca o início, efetivo, do Sustentáculos, a iniciativa circense que nasceu da morte, há 25 anos.

\section{$O$ andamento}

A dinâmica das aulas e do próprio grupo de circenses possui peculiaridades notáveis que são inclusive passíveis de serem percebidas com estranheza num primeiro momento. A começar que as aulas são conduzidas pela professora e idealizadora do projeto enquanto essa está sentada numa cadeira, próxima aos tatames, utilizando de comandos predominantemente verbais. Tamanho é o respeito que os/as alunos(as) possuem por ela, que é uma figura de poder naquela circunscrição, que aprendem os movimentos acrobáticos, contorcionismo, lira e malabarismo basicamente de modo oral - fazendo jus, assim, à tradição circense. No caso de algum aprendiz possuir intensa dificuldade, a ponto de travar em determinada coreografia ou exercício, geralmente os outros alunos intervêm - sob os comandos da professora ou não - a fim de demonstrar corporalmente o entrave e auxiliar o colega; ocasionalmente, a professora também expõe o determinado movimento.

O poder da líder fica ainda mais evidente quando incorporado no "chinelo". O chinelo surge em contextos de demasiada bagunça, agitação e desconcentração dos pequenos, de tal modo que as atividades da aula se tornam secundárias no meio da algazarra e o artifício chama a atenção deles neste sentido. O chinelo é simplesmente tirado do chão e apontado para um dos arteiros-tumultuadores e isso basta para que todos fiquem quietos e, depois de um suspiro de apreensão, riam disso. A punição - que é eficaz visto que a folia cessa - é tida com leveza pelos/as alunos(as), a ponto que é recebida como bronca num formato de brincadeira e descontração, ao contrário do que representa no imaginário social. 
Dessa forma, é cabível apontar que não se trata do que a professora faz, exclusivamente, mas de como faz, o toque e sentido que investe na sua pedagogia autoral. Essa é marcada por uma frontalidade incisiva que dialoga com a disciplina presente no saber e fazer circense, mas que opera também como um cuidado dela para com os alunos. Outro exemplo disso ocorre quando algum membro passa a ausentar-se regularmente das aulas e, consequentemente, a prática circense do aluno e do grupo é afetada; nesse cenário, a artista repreende o/a aluno(a) com falas como "Você virou turista aqui. Tá vendo? Tem que vir no circo para isso!" - apontando para alguém que dominou o exercício. A maneira diretiva e franca dela se impor mostra, em síntese, que o aluno importa: importa para ela, para o grupo, para o circo.

Em termos coletivos, de fato, um membro do circo ausente - ou presente, mas não envolvido - traz impactos para o desenvolvimento de todos. Talvez seja por isso que, como já colocado, existe um movimento natural de dispor-se a um outro ao longo das aulas. Seja em um momento de gratificação do/da colega que finalmente conseguiu ultrapassar uma dificuldade - e então, eles batem palma, comemoram, abraçam-se; ou quando um/uma companheiro(a) ainda não se sente pronto para realizar um movimento e os/as alunos(as) mais antigos(as) desempenham papel de "segurança", contendo uma parte do corpo para que ele/ela não caia, por exemplo. A natureza dessas relações colaborativas e empáticas são pilares do circo como arte e prática corporal, fazendo-se assim igualmente presentes no Sustentáculos.

Neste emaranhado de corporeidade, humor, expressão artística e trabalho em equipe em que as artes circenses são aprendidas e praticadas, também reside seu trunfo: auxiliar pessoas a expressarem sua criatividade, exigindo perseverança e disciplina. Para Spiegel e colaboradores, tais efeitos da intervenção de circo podem ser benéficos na saúde física e mental dos aprendizes, e até mesmo na saúde de suas comunidades (Spiegel et al., 2015). No Sustentáculos, a perseverança e disciplina atuam como esteios das aulas e relações. São incentivadas pela professora, mas também abraçadas pelos/as alunos(as), que inclusive se motivam entre si a continuar tentando, apesar das dificuldades que eventualmente possuem. E tão fundamental quanto persistir é celebrar os ganhos da persistência os acertos, novos exercícios e técnicas aprendidas, as superações. E neste momento, também está a trupe que comemora juntamente as conquistas do grupo, e assim encoraja a perseverança e disciplina para o próximo obstáculo.

\section{$O$ (des)envolvimento}

O alicerce deste projeto de circo é certamente o vínculo, a natureza íntima e estável de relação que a idealizadora pretende construir - e constrói - conjuntamente aos alunos. É esse vínculo que permite o surgimento de demandas pessoais, quer sejam do cotidiano escolar das crianças ou de angústias existenciais acerca da vida. É um vínculo que ultrapassa as fronteiras professor-aluno por assemelhar-se praticamente a uma configuração familiar, em que há o desejo de conhecer o que cada membro está experienciando, assim como de acolher e aconselhar - e assim, participar.

Para Hannes e Uten (2018), a reciprocidade no vínculo entre educador de circo social e aprendizes é crucial: sem ela, a intervenção fica incompleta. Apontam que para a relação ser significativa deve apresentar abertura, conexão não hierárquica, participação do educador nas ações, construção de um espaço seguro e experimentação de uma vivência no "aqui e agora”. Tais responsabilidades competem ao educador de circo social, que no caso do Sustentáculos, essa figura é a artista, professora e idealizadora do projeto de circo, e também 
moradora da mesma comunidade de seus/suas alunos(as). Sem conhecer formalmente e teoricamente as diretrizes do circo social, em sua estrutura original advinda do Canadá, a circense ribeirão-pretana domina tais habilidades de modo extremamente espontâneo e genuíno. Se propõe a criar um espaço seguro, de confiança e trocas significativas com seus/ suas alunos(as), por crer que o circo é parte. Mas não o todo. Talvez circo seja mais o caminho, o veículo de comunicação, entre ela e as demandas que a juventude do bairro enfrenta.

Um caso exemplar para isso ocorreu quando um aluno - extremamente comunicativo e animado - estava ansioso, preocupado e introvertido na aula; rapidamente, as atenções voltaram-se a ele até a sua preocupação ser compartilhada com o grupo. Basicamente, o jovem de 14 anos, que é homossexual, temia que fosse apanhar do pai ao chegar em casa, pois ele havia descoberto um episódio que abarcava sua orientação sexual - até então desconhecida pelos familiares. O posicionamento da líder, acompanhada pelas alunas, foi no sentido de amparar e tentar atenuar as tensões e conflitos do menino, através de discursos que o valorizassem como indivíduo: "Você não é só gay, ser gay é uma característica sua, mas você é mais um monte de coisas" - recorte do discurso da professora, que repercutiu em falas das alunas como - "Vocêe é amigo, você é companheiro, você tá ali pra tudo o que eu preciso sempre!" ou "Olha como você é lindo menino, você é muito especial, só precisa se lembrar disso".

A construção de um espaço em que cargas dessa qualidade sejam cabíveis é um dos anseios da autora do projeto por ela reconhecer, nas suas próprias palavras, que "às vezes, tudo o que eles querem é se abrir, sabendo que serão escutados sem crítica e perturbação" e porque "se eles não falarem o que pensam, por medo de serem punidos, vão se tornar adultos reprimidos, sem voz". Em sua fala, evidencia-se a importância que ela atribui ao ato de dividir-se com alguém, o que é algo trazido da relação paterna, em que julga ter aprendido grande parte do que ela sabe hoje - destacando a dignidade e o respeito - devido ao costume diário de conversar com o pai e ouvi-lo discursar sobre a vida. Para colocar em prática esse movimento no grupo, a líder adota estratégias de rodas de conversa, cujas temáticas tangenciam as relações intergrupais, os possíveis planos e espetáculos futuros, modos de arrecadar fundos, vivências pessoais que os membros precisam ou gostariam de compartilhar e, finalmente, conselhos e manifestações variadas dela: a matriarca da família circense.

Para além do amparo proporcionado nas aulas e rodas de conversa, é interessante sublinhar que os amigos do circo são para além do circo. Por viverem na comunidade e estudarem praticamente todos na mesma escola, o convívio entre eles é intenso; no entanto, não se trata apenas de uma intersecção recorrente de universo e atividades, e sim de um investimento constante na ligação que advém do circo e que também encontrou formas de sustentar-se em outros contextos: como nos passeios pelo bairro, nas turmas do colégio, entre as famílias. Nas palavras de uma das alunas, de 12 anos, "todo mundo aqui é irmão", o que reflete o caráter firmado e próximo dos vínculos.

\section{O imbricamento}

Considerando o formato da intervenção, incluindo as peculiaridades e natureza da relação intergrupo, o Sustentáculos opera como um ambiente de cuidado quanto à pessoa que os infanto-juvenis são e podem ser - por oferecer estímulos artísticos, psíquicos e sociais a fim de ampliar o leque de possibilidades do futuro dos alunos. Nas palavras da autora da iniciativa: "Eu não quero que eles sejam necessariamente artistas de circo: eles só precisam ser alguém por escolha deles, serem pensantes”. 
A abordagem da professora, que se apropria sobretudo do circo para passar essas mensagens, é coerente com o que McCaffery (2014) discorre acerca do circo social como uma intervenção de priorização do crescimento pessoal e social dos participantes. Para tal, incentiva o desenvolvimento da autoestima e a aquisição de habilidades sociais, a fim de que os pequenos descubram, explorem e se realizem no seu próprio potencial, “deixando suas contribuições como cidadãos no mundo" (McCaffery, 2014, p. 33). No entanto, no circo Sustentáculos há uma ferramenta a mais que atua nessa direção e que é parte costumeira dos encontros - as rodas de conversa. Atuam como uma formação político-cultural que a líder se incumbe de oferecer. Ensina sobre os marcos da história do Brasil e reflete acerca do cenário político nacional; promove uma conscientização de classe ao explicar a respeito da lógica capitalista protagonizada pela burguesia e sustentada pelo proletariado; empresta livros aos alunos, recomenda filmes e mostra músicas de samba e MPB - que são, geralmente, utilizadas como tema nas apresentações.

Junto a isso, conversa sobre as limitações que o meio social deles impõe, mas lembrando-os que é possível vencê-las e atravessá-las - "o mundo vai além dessa casquinha de ovo” ela alega. Dessa forma, os convida a ver além, a ter um sonho profissional neste circo, todos sabem o que querem ser quando crescer - e estabelecer metas de como atingi-lo. Nesse sentido, ela também ajuda: explica a importância de levarem a escola a sério e aproveitarem ao máximo os professores, porque o fim do processo é uma prova dificílima, mas que garante acesso às melhores universidades, que são públicas. Constrói seu discurso num tom de extremo encorajamento, como "todo mundo é bom em alguma coisa, não é diferente com vocês - com esforço vocês sabem que conseguem" ao mesmo tempo que utiliza de doses de choque, tal qual "vocês podem ser mais do que atendentes do McDonalds". Assim, o mundo e todos os desafios viram um circo, de tal modo que com paixão, dedicação, habilidade e esforço, os sonhos tornam-se possíveis e os objetivos alcançáveis.

Nesse entrelaçado motivacional-impactante, a líder simboliza o circo como esta ponte preparatória para os ensinamentos da vida real, destacando a persistência e a disciplina, aprendidas inerentemente nas aulas, como fatores cruciais para ter coragem de ser aquilo que se é e que se sonha. A tolerância à frustração também é destacada como aquisição potente, visto que "mesmo quem já é muito bom, tem de conviver com o erro", como declara a líder. Por fim, uma contribuição expressiva é provar aos alunos que eles possuem um valor idiossincrático, que desfrutam de uma série de potencialidades e que são capazes de superar as dificuldades que marcarem seus caminhos. Como o caso de um ex-aluno da idealizadora do Sustentáculos, que era gago e se diminuía por ter vergonha da gagueira; em um espetáculo, ela o fez locutor - embora um primeiro receio e recusa do aluno - e, depois desse evento, em que ele se apropriou como estrela de uma condição que o fazia mal, a gagueira foi superada.

\section{Discussão e considerações finais}

Facilmente as afinidades centrais entre as propostas do circo social e do circo periférico Sustentáculos são notadas, uma vez que o cerne de ambas é a arte circense como dispositivo de impacto em vidas e histórias. No entanto, o que é no mínimo curioso desponta em como tais projetos nasceram, independentemente um do outro, em terrenos socioculturais completamente distintos, e ainda assim compartilham de uma identidade em suas práticas e pretensões. Seria a impregnante força e carga iniciática do circo 
o impulsionador desses movimentos? De tal modo que essa energia se imprime em sujeitos líderes que atuam como porta-vozes e, assim, fazem o circo ser percebido a partir desse potencial-transformador que inerentemente carrega?

Certamente, não há respostas óbvias e diretas acerca de tais questionamentos; mas o que se presume a partir de experiências trazidas neste estudo - e também através das apontadas nas pesquisas que envolvem o circo social - é que há uma marca pelo encontro e que se trata de um encontro marcante: entre o jovem e a arte circense. Para Clarice Lispector (1978), "o que verdadeiramente somos é aquilo que o impossível cria em nós" (p. 245) e por esse viés de reflexão, o circo simbolicamente vive e alimenta-se do impossível que se apresenta a cada um de seus eterno-aprendizes. É o impossível que os mantém conectados e engajados como grupo e como indivíduos, pois há um "entre" constante: do erro ao acerto, do que já se conhece ao que se sonha dominar, do que se domina e do que nunca irá ser perfeitamente dominado - embora toda a disposição e capacitação.

Para além da marca circense que fortemente faz-se presente nas duas propostas, algo que é obviamente comum é o fato de ambas trabalharem com crianças e jovens marginalizados. Hurtubise, Roy e Bellot (2003) colocam que há uma ligação entre o universo circense e o mundo da rua na medida em que "nômades, ciganos e peregrinos desempenham um papel preponderante na história do circo e nas ocupações de artes de rua" (p. 405) havendo assim uma predisposição do circo ser abraçado e sentido como pertencente por parte dos participantes, devido a uma raiz cultural próxima entre a rua e a periferia.

Porém, em termos de como se estabelecem e se dão as relações entre os projetos e tal população, há uma diferença que é significativa. O circo social possui como principal propósito a inclusão dos infanto-juvenis marginalizados e utiliza dos recursos circenses transpostos para a vida como meio para tal; o Sustentáculos igualmente contém como objetivo a desmarginalização, mas, para além da arte circense, apropria-se de um cunho político e contestador a fim de conscientizar, provocar e, assim, tentar gerar movimento nos alunos para que se esforcem e busquem novas possibilidades que não exclusivamente as disponíveis no meio periférico.

Mais um contraste que, em síntese, sistematiza essas questões, diz respeito ao circo social possuir um esteio pedagógico, uma vez que é sobretudo função do instrutor ensinar a prática e do educador - que não é circense - refletir sobre como ela não se limita às lonas. Já no Sustentáculos, há um pilar do artístico propriamente dito que se reverbera a partir da promotora da iniciativa, que antes de professora é circense da periferia, e que sendo a única figura que encabeça, ensina e propaga o circo, apresenta aos alunos essas múltiplas posições condensadas. Ficam imbricadas a idealizadora, professora e artista, o que garante a riqueza da intervenção.

Extrapolando os contrastes, uma reflexão que desponta quanto às intervenções reside em por que a utilização do circo é tomada como instrumento de desenvolvimento integral dos/das participantes ao invés de qualquer outra mediação artístico-cultural: ou seja, por que circo? E não música ou dança? Há uma contribuição inerente e específica da estrutura do circo, a tal ponto que ele se manifesta e propicia ganhos, independente do contexto sociocultural em que se presentifica? Para Lafortune e Bouchard (2010), a potência própria do circo para os feitos sociais com essa população reside justamente no convite à expressão da liberdade e criatividade, exigindo coragem, disciplina e perseverança, além da necessidade interacional profunda que necessita confiança e entrega entre os membros do coletivo. Dessa maneira, um valor possível do circo se sustenta nesse cruzamento 
apreendido teoricamente, mas também é certo que há uma instância enigmática da arte circense que só se apresenta para aqueles que a vivem e que a sentem - e que, portanto, se mostra como um vazio para este estudo, mas impulsionador para possíveis investigações futuras que podem se engendrar nesse sentido.

Por fim, mais importante do que a configuração em que o circo é expresso ou apresentado como um convite para que o seja, é que ele, de fato, esteja presente no universo da rua e da periferia - em casa. E que os recursos simbólicos eminentes de sua presença e prática sejam primeiramente ouvidos, para então serem compreendidos em sua magnitude e utilizados como caminho para a transformação e ampliação da existência dos pequenos. Ou seja, como coloca Hassan (2006): "Espera-se que a criança ou adolescente não desafie apenas a gravidade, mas também os problemas e obstáculos da vida, potencializando cada vez mais a compreensão do seu estar no mundo” (p. 1). E, assim, assuma o protagonismo do espetáculo da vida que ininterruptamente se engenha, cujo papel já lhe é dado e lhe é exclusivo, mas nem por isso fácil.

\section{Referências}

Bairrão, J. F. M. H. (2005). A escuta participante como procedimento de pesquisa do sagrado enunciante. Estudos de Psicologia (Natal), 10(3), 441-446. https://doi.org/10.1590/S1413$\underline{-294 \times 2005000300013}$

Bairrão, J. F. M. H. (2015). Etnografar com Psicanálise. Psicologias de um ponto de vista empírico. Cultures-Kairós Revue d'anthropologie des pratiques corporelles et des arts vivants, 5. http://revues.mshparisnord.org/cultureskairos/index.php?id=1197

Bolognesi, M. F. (2001). O corpo como princípio. Trans/Form/Ação, 24(1), 101-112. https:// doi.org/10.1590/S0101-31732001000100007

Elia, L. (1999). A transferência na pesquisa em psicanálise: lugar ou excesso? Psicologia: Reflexão e Crítica, 12 (3). https://doi.org/10.1590/S0102-79721999000300015

Castro, A. V. (2003). O circo no Brasil através dos tempos. In Revista Circo do Mundo Brasil. Uma proposta metodológica em rede (pp. 30-31). Rio de Janeiro: FASE.

Fonseca, C. (1999). Quando cada caso NÃO é um caso. Revista Brasileira de Educação, 10, 58-78.

Freud, S. (1913). Recomendações aos médicos que praticam a psicanálise. In: Edição Standard Brasileira das Obras Psicológicas Completas de Sigmund Freud.Vol. XII. Rio de Janeiro, Imago Editora, 1969. p. 147-159.

Hannes, K. \& Uten, L. (2018). On the act of giving, receiving and rendering: Piloting the use of Youtube vídeos to develop a contextually inspired portrait of social circus trainers. Learning, Culture and Social Interaction 19, 96-108.

Hassan, A. P. (2006). O circo social e a possibilidade de construção de uma nova prática educativa para classes populares: um relato de experiência das percepções e vivências de educadores sociais. In Anais, I Congresso Internacional de Pedagogia Social. Universidade de São Paulo. http://www.proceedings.scielo.br/scielo.php?script=sci arttext\&pid=M$\underline{\text { SC0000000092006000100005\&lng }=e n \& n r m=a b n}$.

Hurtubise, R., Roy, E., \& Bellot, C. (2003). Youth homelessness: The street and work - from exclusion to integration. In L. Roulleau-Berger (Ed.), Youth and work in the post-industrial city of North America and Europe (pp. 395-407). Brill Academic. 
Lafortune, M. \& Bouchard, A. (2011). Community worker's guide: when circus lessons become life lessons, Cirque du Soleil. Fondation Cirque du Soleil. http://holisticcircustherapy.com/ ufiles/library/Social Circus Guide.pd

Laplantine, F. (2004). A descrição etnográfica. Terceira Margem.

Leal Barros, M. \& Bairrão, J. F. M. H. (2010). Etnopsicanálise: embasamento crítico sobre teoria e prática terapêutica. Revista da SPAGESP, 11 (1), 45-54.

Lispector, C. (1978). A maçã no escuro. Paz e Terra.

Lobo, L. \& Cassoli, T. (2006). Circo social e práticas educacionais não governamentais. Psicologia e Sociedade, 18(3), 62-67. https://doi.org/10.1590/S0102-71822006000300009

Manzini, E. J. (2004). Entrevista semi-estruturada: análise de objetivos e de roteiros. In Seminário Internacional Sobre Pesquisa e Estudos Qualitativos, 2. Bauru, SP. Anais. A pesquisa qualitativa em debate.

McCaffery, N. (2014). Social Circus and Applied Anthropology - A Synthesis Waiting to Happen. Anthropology in Action, 21(1), 30-34. https://doi.org/10.3167/aia.2014.210106

Oliveira, J. S. \& Cavedon, N. R. (2013). Micropolíticas das práticas cotidianas: etnografando uma organização circense. Revista de Administração de Empresas, 53(2), 156-168. https://doi. org/10.1590/S0034-75902013000200004

Pagliuso, L. J. \& Bairrão, J. F. M. H. (2015). Etnopsicologia no Brasil: um breve histórico. In J. F. M. H. Bairrão \& M. T. A. D. Coelho (Orgs.), Etnopsicologia no Brasil: teorias, procedimentos e resultados (pp. 17-47). Editora da Universidade Federal da Bahia. http://repositorio.ufba.br/ $\underline{\mathrm{ri} / \mathrm{handle} / \mathrm{ri} / 18029}$

Pereira, E. R. \& Maheirie, K. (2016). Aprendiz circense e contemplador: olhares que dialogam entre a incompletude e o acabamento. Fractal: Revista de Psicologia, 28(1), 134-138. https://doi.org/10.1590/1984-0292/1179

Ravasio, M. T. H. (2014). Tempos, movimentos e escrita: experiência de escuta analítica de professoras. Tese de Doutorado, Programa de Pós graduação em Educação, Universidade Federal do Rio Grande do Sul, Porto Alegre.

Revista Circo do Mundo Brasil. (2003). Uma proposta metodológica em rede. Rio de Janeiro: FASE.

Rivard, J., Bourgeault, G., \& Mercier, C. (2010). Cirque du monde in Mexico City: Breathing new life into action for young people in difficult situations. The Social Science Journal, 61(199), 181-199.

Silva, E. (1996). O circo: sua arte e seus saberes - o circo no Brasil no final do século XIX a meados do XX. Dissertação de Mestrado, Programa de Pós graduação em Filosofia e Ciências Humanas, Universidade Estadual de Campinas, SP.

Souza, A. C. (2013). Milton Nascimento: el circo como lugar de resistência cultural. Historia Actual Online, 30, 193-200.

Spiegel, J. B. \& Parent, S. N. (2018). Re-approaching community development through the arts: a 'critical mixed methods' study of social circus in Quebec. Community Development Journal, 53(4), 600-617.

Spiegel, J. B., Breilh, M.-C., Campaña, A., Marcuse, J., \& Yassi, A. (2015). Social circus and health equity: Exploring the national social circus program in Ecuador. Arts $\&^{2}$ Health 7(1), 65-74. 


\section{Agradecimentos e Agência de Fomento}

Dedicamos este trabalho primeiramente aos colaboradores, que nos permitiram experimentar um pouco do mistério e da garra do circo que os habita e que deixaram-se (e o deixaram) em nós, a cada encontro. Agradecemos aos nossos colegas de Laboratório, à trupe que dá força para que este espetáculo continue. Por fim, demonstramos sincera gratidão à Fundação de Amparo à Pesquisa do Estado de São Paulo por também acreditar e investir na pesquisa que deu origem ao artigo - processo nº 2017/26412-4.

\section{GIOVANA TONINI \\ https://orcid.org/0000-0001-6605-8561}

Graduanda em Psicologia na FFCLRP (Faculdade de Filosofia Ciências

e Letras de Ribeirão Preto) pela Universidade de São Paulo (USP).

End.: Avenida Bandeirantes 3900, CEP: 14040-905, Universidade de São

Paulo (USP), Ribeirão Preto.

E-mail: giovanatonini@gmail.com

\section{JOSÉ FRANCISCO MIGUEL HENRIQUES BAIRRÃO \\ https://orcid.org/0000-0001-6372-8873}

Professor Associado do Departamento de Psicologia da FFCLRP (Faculdade

de Filosofia Ciências e Letras de Ribeirão Preto) da Universidade de São

Paulo (USP).

E-mail: bairrao@usp.br

\begin{tabular}{|c|c|}
\hline Histórico & $\begin{array}{l}\text { Submissão: 17/09/2019 } \\
\text { Revisão: 24/06/2020 } \\
\text { Aceite: 03/07/2020 }\end{array}$ \\
\hline $\begin{array}{l}\text { Contribuição } \\
\text { dos autores }\end{array}$ & $\begin{array}{l}\text { Concepção: G.T.T.; J.F.M.H.B. } \\
\text { Coleta de dados: G.T.T. } \\
\text { Análise de dados: G.T.T.; J.F.M.H.B. } \\
\text { Elaboração do manuscrito: G.T.T.; J.F.M.H.B. } \\
\text { Revisões críticas de conteúdo intelectual importante: } \\
\text { G.T.T.; J.F.M.H.B. } \\
\text { Aprovação final do manuscrito: G.T.T.; J.F.M.H.B. }\end{array}$ \\
\hline $\begin{array}{l}\text { Aprovação, ética } \\
\text { e consentimento }\end{array}$ & Não se aplica. \\
\hline Financiamento & $\begin{array}{l}\text { FAPESP - Fundação de Amparo à Pesquisa do Estado de São Paulo. } \\
\text { Bolsa de Iniciaçâ Científica, recebida durante } 2 \text { anos: contrato de } \\
\text { novembro/2018 a novembro/2020. } \\
\text { Número do processo: } 2017 / 26412-4 \text {. } \\
\text { Linha de fomento/divulgação: Iniciação Científica/Fluxo Contínuo } \\
\text { Título: O respeitável público: arte circense e processos biográficos. }\end{array}$ \\
\hline
\end{tabular}

